\title{
Proceeding Paper \\ Reproductivity Study of Metal Oxide Gas Sensors Using Two Different Temperature Setups ${ }^{\dagger}$
}

\author{
Giulia Zambotti 1,2,*(D) and Andrea Ponzoni 1,2 (D) \\ 1 National Research Council, National Institute of Optics (CNR-INO), Unit of Brescia, Via Branze 45, \\ 25123 Brescia, Italy; andrea.ponzoni@ino.cnr.it \\ 2 Department of Information Engineering, University of Brescia, Via Branze 38, 25123 Brescia, Italy \\ * Correspondence: giulia.zambotti@ino.cnr.it \\ + Presented at the 1st International Electronic Conference on Chemical Sensors and Analytical Chemistry, \\ 1-15 July 2021; Available online: https://csac2021.sciforum.net/.
}

check for

updates

Citation: Zambotti, G.; Ponzoni, A. Reproductivity Study of Metal Oxide Gas Sensors Using Two Different Temperature Setups. Chem. Proc. 2021, 5, 26. https://doi.org/10.3390/ CSAC2021-10613

Academic Editor:

Nicole Jaffrezic-Renault

Published: 6 July 2021

Publisher's Note: MDPI stays neutral with regard to jurisdictional claims in published maps and institutional affiliations.

Copyright: (C) 2021 by the authors. Licensee MDPI, Basel, Switzerland. This article is an open access article distributed under the terms and conditions of the Creative Commons Attribution (CC BY) license (https:// creativecommons.org/licenses/by/ $4.0 /)$.

\begin{abstract}
The use of the electronic nose as a screening device is of great interest in various types of applications, including food quality control and environmental monitoring. It is an easy-to-use device and produces a much faster response than that obtained by classical chemical and microbiological techniques. The reproductivity of nominally identical electronic noses and sensors is critical. Four identical MOX sensors were compared using two different working methods, namely, the temperature modulation mode and isothermal mode. Each sensor was tested with two standard compounds, water and lactic acid, often identified in food matrices, which are potential applications of the electronic nose.
\end{abstract}

Keywords: sensor reproductivity; modulation of temperature; isothermal mode; electronic nose; MOX sensors

\section{Introduction}

Sensor reproductivity is an important issue to ensure the reliability of the final instrument, such as electronic noses, in which individual sensors are implemented [1]. The core of the electronic nose is made of an MOX sensor array [2], which may work in isothermal and/or temperature modulation mode. These two different types of working modes can affect the sensitivity of the sensor in respect to the gases.

For temperature modulation, a periodic signal is applied to the heater to periodically change the sensor temperature in order to activate and inactivate the oxidation-reduction reactions between the sensitive material and gases [3,4]. As a consequence, the sensor resistance changes periodically with time, and parameters describing this curve can be extrapolated and used as input (features) to the pattern recognition algorithm. These parameters play the same roles as those attributed to the responses of individual sensors that work at a constant temperature, i.e., a fixed voltage applied to the heater [5].

Electronic noses have been used for different types of applications, for example, in the environmental field [6], medicine [7], security and safety [8], and food control [9,10].

For commercial applications (medical, food, environmental), three different aspects are important to develop an effective electronic nose: the system must guarantee good performance in order to achieve sensitivity and specificity; the database and the pattern recognition software should work on different nominally identical electronic noses with minimal adaptation work; and sensors should be interchangeable with nominally identical ones in case of failure. For these reasons, in this work, the reproductivity of nominally identical sensors was tested comparing the features extrapolated with sensors working in the two modes: isothermal and temperature modulation. 


\section{Material and Methods}

In this work, we used a JLM MOX STICK (JLMInnovation Gmbh) device (Figure 1) to perform experiments. This instrument includes sensor control software and the electronic part. The experiments were conducted using 4 commercial sensors (TGS 2620—Figaro Sensor) exposed to vapors from a pure solution of water and lactic acid.

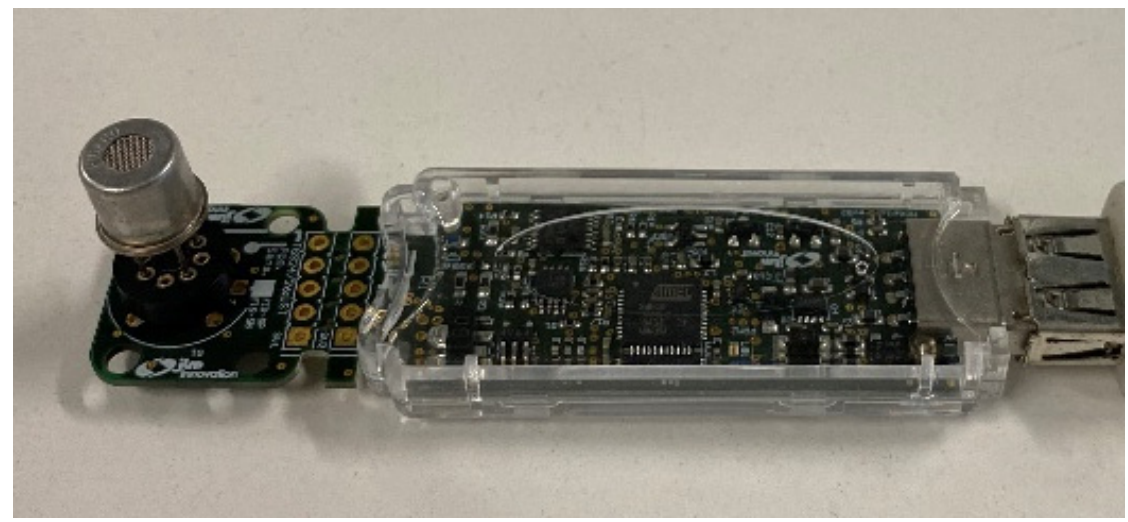

Figure 1. JLM MOX STICK device (JLMInnovation Gmbh) equipped with a commercial (Figaro TGS2620) sensor.

For the constant temperature mode, each sensor was tested with a constant voltage of 3.5 applied to the heater. For temperature modulation, the first part of the period lasted $10 \mathrm{~s}$ (4 volts) and the second part of the period lasted $10 \mathrm{~s}$ ( 3 volts). We chose these voltage and time values to have the same average temperature for both modes during a single thermal period.

Each sensor was turned on and exposed to ambient air (environmental temperature $21^{\circ} \mathrm{C}$ ) for one hour in order to stabilize it before performing the planned series of measurements.

Two vials were prepared using $10 \mathrm{~mL}$ of water and $10 \mathrm{~mL}$ of lactic acid. Both were sealed with parafilm and left in the room for one hour to create the headspace. A hole was then created in the parafilm, and the sensor was inserted. Measurement times were as follows: $10 \mathrm{~min}$ in contact with the compound vapors and $10 \mathrm{~min}$ in air to allow for baseline recovery. Each substance was replicated 3 times.

The following features were used for the elaboration on the temperature modulation dataset and to describe the resistance versus time curve. Using this method of measurement, it is possible to extrapolate several features to be used to analyze the data, unlike the isothermal method that allows the processing of a single parameter, $\mathrm{R} / \mathrm{R} 0$. The value of $\mathrm{R} / \mathrm{R} 0$ was calculated using the minimum resistance value reached by the gas in contact with the sensor (R), divided by the starting value of the sensor in air (R0). For the temperature modulation method, 2 significant features were extrapolated:

- $\quad$ Ratio- $\mathrm{CH}=$ ratio between the sensor resistance identified at the end of the cold halfperiod and at the beginning of the next hot half-period, i.e., Ratio- $\mathrm{CH}=\mathrm{R} 2 / \mathrm{R} 3$.

- DeltaR-C = change in sensor resistance measured during the cold half-period, i.e., DeltaR-C = R1 - R2.

All of this information is shown in Figure 2. 


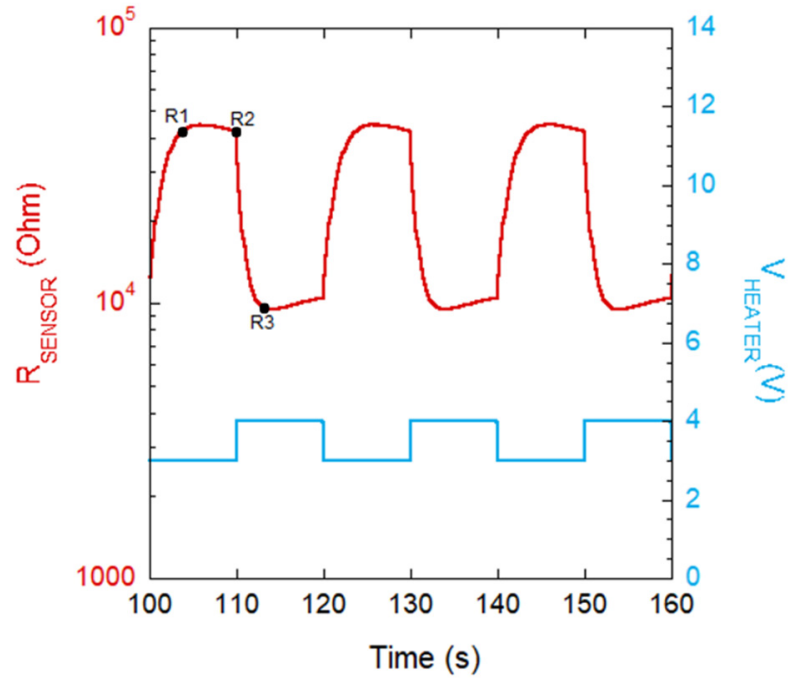

(a)

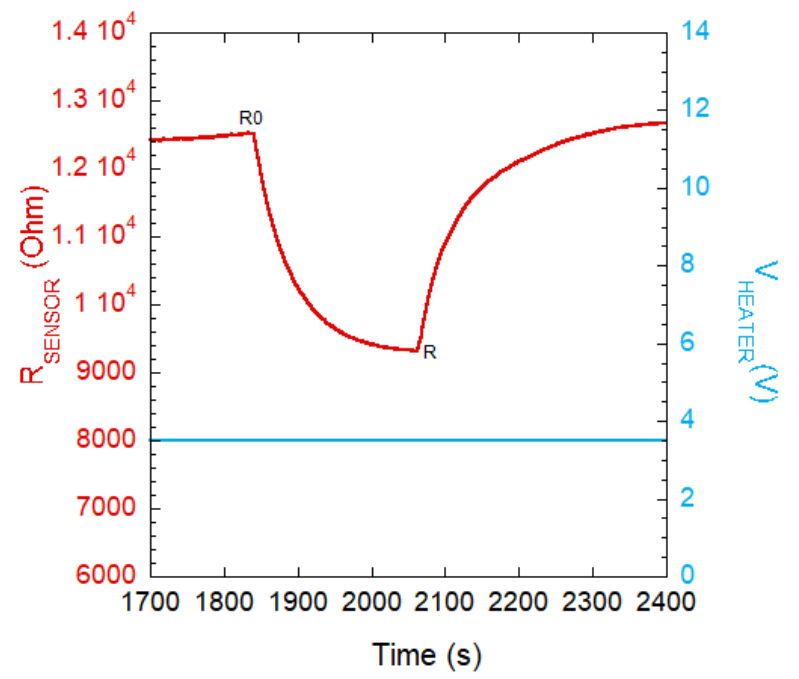

(b)

Figure 2. (a) The light blue line represents the modulation of the heater voltage between 3 and 4 volts. The red curve is an example of sensor resistance measured during exposure to water vapors. DeltaR-C = R1 - R2; Ratio- $\mathrm{CH}=\mathrm{R} 2 / \mathrm{R} 3$. (b) The isothermal example shows the voltage applied to the heater with a light blue line, while the red curve shows an example of sensor resistance measured during exposure to water vapors (response calculated as R/R0).

\section{Results and Discussion}

Based on our previous experience of food quality control applications [9], we chose the most significant features (Ratio- $\mathrm{CH}$ and $\mathrm{R} / \mathrm{R} 0$ ) to compare the results obtained from each individual sensor. The statistics of the recorded responses are shown in Figure 3.

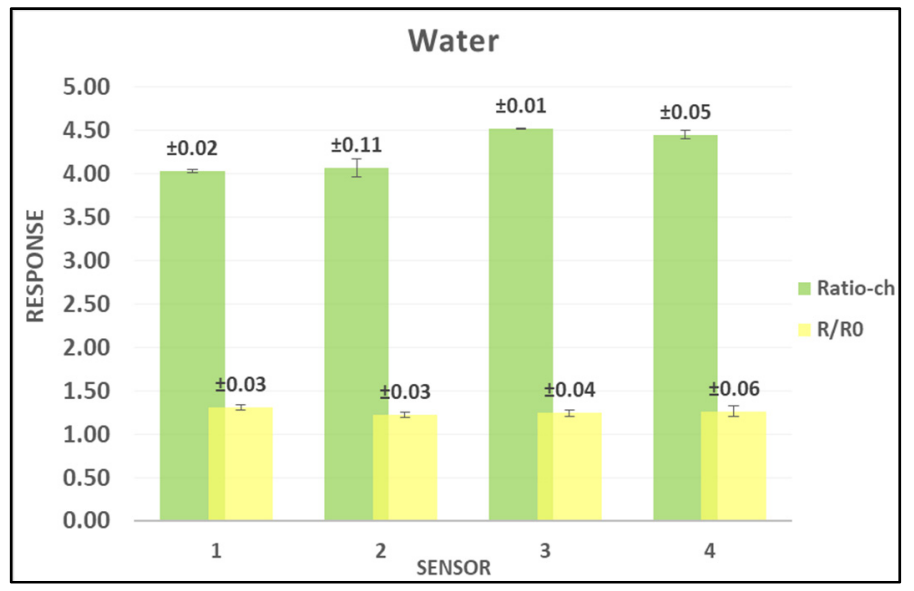

(a)

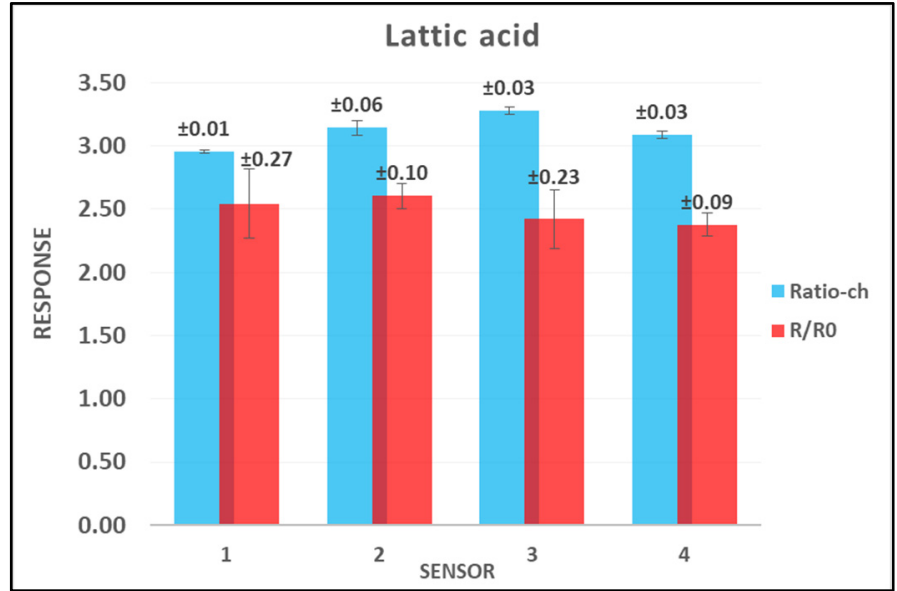

(b)

Figure 3. (a) Comparison between Ratio- $\mathrm{CH}$ (green color) and $\mathrm{R} / \mathrm{R} 0$ (yellow color) response to water vapors. (b) Response obtained to lactic acid vapors. Light blue rectangles relate to Ratio- $\mathrm{CH}$, while red rectangles concern $\mathrm{R} / \mathrm{R} 0$.

The value of each single response is the average of the single values obtained during the measurement session (replicated three times). The graphs also show the standard deviation corresponding to each result.

The first thing to note is that for both compounds analyzed and for both methods used, the sensors return a reproducible response. Evaluating, in detail, the response obtained by each method, we can see that the standard deviation (absolute value) for temperature modulation is always lower than that obtained using the isothermal method. This is further 
enhanced by normalizing the standard deviation to the average of the response intensity. Indeed, concerning water, the value changes from $0.5 \%$ to $2.6 \%$ for Ratio- $\mathrm{CH}$, while for $\mathrm{R} / \mathrm{R} 0$, it changes from $2.25 \%$ to $4.65 \%$. It is possible to note the same situation in the measure of lactic acid (Ratio-CH 0.5-3.9\%, R/R0 3.80-10.74\%).

During the experience gained using the temperature modulation method, we realized that one of the features that introduce a large amount of information in the construction of the PCA (principal component analysis) plot is DeltaR-C, and therefore we decided to analyze it [7-9].

As can be seen in Figure 4, the reproductivity of the sensors towards the analyzed compounds is relatively poor in respect to what was observed concerning the Ratio- $\mathrm{CH}$ feature. There is an appreciable variance from sensor to sensor and within individual measurements. We find a standard deviation that ranges from $5.3 \%$ to $63 \%$ (water) and from $2.5 \%$ to $27.6 \%$ (lactic acid). However, in any case, it is able to return the most important information combined with other extracted features [7-9]. This means that the reproductivity of sensors depends on the given feature analyzed.

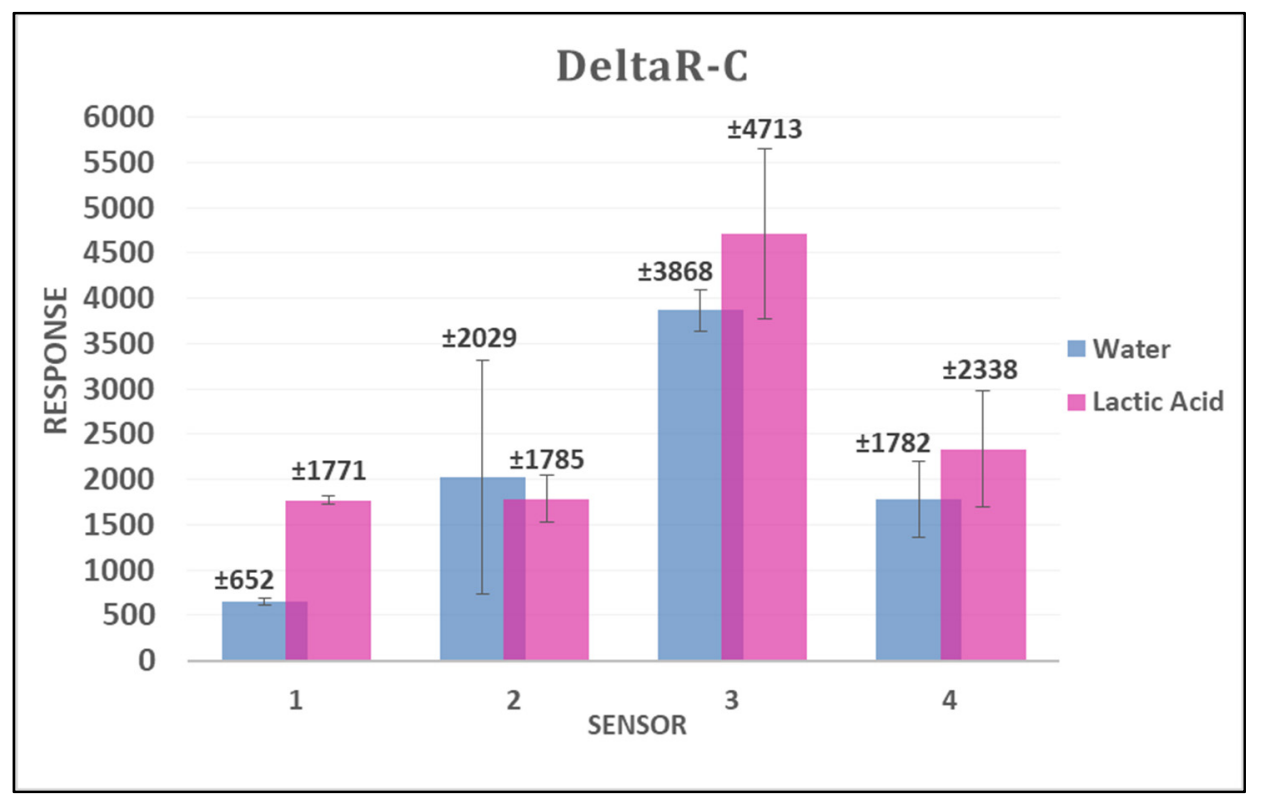

Figure 4. Sensor responses measured during exposure to water and lactic acid vapors.

\section{Conclusions}

In conclusion, two features were extrapolated and analyzed during experiments carried out using temperature modulation. Both these features were revealed to be useful during our old experiments dedicated to the detection of fish shelf life. The reproductivity of nominally identical sensors showed feature dependence, i.e., the feature Ratio- $\mathrm{CH}$ is better than the feature DeltaR-C. For a constant temperature, the normalized feature may be more or less repeatable than that extrapolated from the other mode depending on individual features, though the response extrapolated from this working mode benefits from the normalization to the reference air, while this does not occur for the temperature modulation mode.

Supplementary Materials: The following are available online at https:/ / www.mdpi.com/article/10 .3390/CSAC2021-10613/s1.

Author Contributions: Conceptualization, G.Z. and A.P.; methodology, G.Z. and A.P.; resources, G.Z. and A.P.; data curation, G.Z. and A.P.; writing—original draft preparation, G.Z. and A.P.; writingreview and editing, G.Z. and A.P. All authors have read and agreed to the published version of the manuscript. 
Funding: This research was funded by Lombardia region and Fondazione Cariplo through the project EMPATIA@LECCO.

Institutional Review Board Statement: Not applicable.

Informed Consent Statement: Not applicable.

Data Availability Statement: The main data have been reported in figures (mean and std). Additional data are available from the corresponding author upon reasonable request.

Conflicts of Interest: The authors declare no conflict of interest.

\section{References}

1. Zonta, G.; Astolfi, M.; Casotti, D.; Cruciani, G.; Fabbri, B.; Gaiardo, A.; Gherardi, S.; Guidi, V.; Landini, N.; Valt, M.; et al. Reproducibility tests with zinc oxide thick-film sensors. Ceram. Int. 2020, 46, 6847-6855. [CrossRef]

2. Ponzoni, A.; Baratto, C.; Cattabiani, N.; Falasconi, M.; Galstyan, V.; Nunez-Carmona, E.; Rigoni, F.; Sberveglieri, V.; Zambotti, G.; Zappa, D. Metal Oxide Gas Sensors, a Survey of Selectivity Issues Addressed at the SENSOR Lab, Brescia (Italy). Sensors 2017, 17, 714. [CrossRef] [PubMed]

3. Krivetskiya, V.; Efitorov, A.; Arkhipenko, A.; Vladimirova, S.; Rumyantseva, M.; Dolenko, S.; Gaskov, A. Selective detection of individual gases and $\mathrm{CO} / \mathrm{H}_{2}$ mixture at low concentrations in air by single semiconductor metal oxide sensors working in dynamic temperature mode. Sens. Actuators B Chem. 2018, 254, 502-513. [CrossRef]

4. Hosseini-Golgoo, S.M.; Hossein-Babaei, F. Assessing the diagnostic information in the response patterns of a temperaturemodulated tin oxide gas sensor. Meas. Sci. Technol. 2011, 22, 035201. [CrossRef]

5. Soprani, M.; Zambotti, G.; Ponzoni, A. Response Times of Metal-Oxide Chemiresistors: Comparison Between the Isothermal and Temperature Modulation Modes. J. Nanosci. Nanotechnol. 2021, 21, 2668-2674. [CrossRef] [PubMed]

6. Al Barakeh, Z.; Breuil, P.; Redon, N.; Pijolat, C.; Locoge, N.; Viricelle, J.-P. Development of a normalized multi-sensors system for low cost on-line atmospheric pollution detection. Sens. Actuators B Chem. 2017, 241, 1235-1243. [CrossRef]

7. Soprani, M.; Zambotti, G.; Gobbi, E.; Ponzoni, A. Application of a Micro-Machined Electronic Nose to Detect Escherichia Coli in Human Urine Samples. In Proceedings of the 8th GOSPEL Workshop, Gas Sensors Based on Semiconducting Metal Oxides: Basic Understanding \& Application Fields, Ferrara, Italy, 20-21 June 2019. [CrossRef]

8. Vezzoli, M.; Ponzoni, A.; Pardo, M.; Falasconi, M.; Faglia, G.; Sberveglieri, G. Exploratory data analysis for industrial safety application. Sens. Actuators B Chem. 2008, 131, 100-109. [CrossRef]

9. Zambotti, G.; Soprani, M.; Gobbi, E.; Capuano, R.; Pasqualetti, V.; Di Natale, C.; Ponzoni, A. Early detection of fish degradation by electronic nose. In Proceedings of the IEEE International Symposium on Olfaction and Electronic Nose (ISOEN), Fukuoka, Japan, 26-29 May 2019. [CrossRef]

10. Gobbi, E.; Falasconi, M.; Zambotti, G.; Sberveglieri, V.; Pulvirenti, A.; Sberveglieri, G. Rapid diagnosis of Enterobacteriaceae in vegetable soups by a metal oxide sensor based electronic nose. Sens. Actuators B Chem. 2015, 207, 1104-1113. [CrossRef] 